\title{
EXTERNALIDADES E FORMAÇÃO DE PREÇOS NO MERCADO IMOBILIÁRIO URBANO BRASILEIRO: UM ESTUDO DE CASO*
}

\author{
Ronaldo A. Arraes ${ }^{\S}$ \\ Edmar de Sousa Filho
}

\begin{abstract}
RESUMO
Este artigo consiste no estudo dos determinantes econômicos e externalidades que contribuem para a formação dos preços no espaço urbano de uma cidade brasileira de porte médio - Fortaleza, Estado do Ceará -, fundamentado na teoria dos preços hedônicos ou preços implícitos. O modelo proposto investiga preços implícitos na curva de utilidade de um agente de demanda segmentado em dois grupos: consumidor direto do bem habitação e o investidor em imóveis, que incorpora adicionalmente atributos econômico-financeiros que medem o grau de risco e retorno na formação dos preços. O estudo estima os preços hedônicos por meio de um modelo segmentado por tipo de imóvel contra os diversos atributos distribuídos nos vetores de características físicas, locacionais, econômicas e financeiras. A amostra é formada pelas transações imobiliárias ocorridas no período 1995-2003, perfazendo o total de 4.467 observações, distribuídas em apartamentos, flats, terrenos e salas comerciais.
\end{abstract}

Palavras-chave: mercado imobiliário urbano, preços hedônicos, flats, sala comercial, Fortaleza.

\begin{abstract}
This paper focuses on the economic determinants that contribute to the formation of the prices of the real estate market of the city of Fortaleza (Ceará), based upon the hedonic or implicit prices theory. The model considered for the work investigates implicit prices in the curve of utility of an agent of demand segmented in two groups: direct consumer of the good house and the investor in properties, that it incorporates economicalfinancial additionally that measure the degree of risk and return in the formation of the hedonic prices. It is estimated the hedonic prices through segmentation by type of property taking into account several attributes distributed in the vectors of physical, location, economical and financial characteristics. The selected sample is formed by the real estate transactions occurred in the city (period from 1995 to 2003), accounting for 4.467 observations distributed among residential apartments, flats, urban lands and commercial offices.
\end{abstract}

Keywords: urban real state market, hedonic prices, flats, office, Fortaleza.

JEL classification: C31, D12, R21.

\footnotetext{
* Os autores agradecem as sugestões dos pareceristas, os quais, certamente, estão eximidos de quaisquer erros que porventura persistam.

$\S$ Professor da Pós-Graduação em Economia, CAEN/UFC.E-mail: ronald@ufc.br.

a Mestre em Economia (UFC) e Administração Financeira (UECE); Gerente de Investimentos Imobiliários, Capef. E-mail: edmar.filho@ig.com.br.

Recebido em setembro de 2005. Aceito para publicação em junho de 2008.
} 


\section{INTRODUÇÃO}

O consumo de habitação é inerente a todo ser humano, sendo caracterizado como necessidade básica e intimamente ligado à busca de segurança contra as adversidades do meio ambiente. Porém, o consumo de habitação pode ser segmentado em dois grandes grupamentos: aqueles que possuem a intenção de utilizar o bem para satisfação final de sua necessidade básica de habitação e aqueles que o adquirem para compor cesta de bens de investimento.

Dado que os agentes econômicos de oferta e demanda são circundados por variáveis determinantes que influem nos resultados finais daquele ato de consumo, nasce aqui um complexo sistema de formação de preço, onde prevalecem a assimetria de informação e as falhas de mercado. Cada consumidor monta sua cesta de anseios, esperando ter resposta na aquisição do bem habitação, a partir de uma substituição ótima entre as diversas características presentes em cada bem. Características essas vinculadas a três vetores preliminarmente primordiais: atributos físicos do bem, vizinhança ou localização ótima e características ambientais inerentes ao imóvel.

Uma vez que o preço final de equilíbrio é função de vetores com distintas características da escolha imobiliária, tem-se como decorrência que, na análise do preço, não somente características físicas do imóvel possuem importância, mas também efeitos de externalidades devem ser considerados (ABRAMO; FARIA, 1998). Ainda, o capital imobiliário envida estratégia de ação para realização de ganhos fundiários, traduzindo-se em externalidades incorporadas aos preços dos imóveis e definindo escolhas de famílias com diferentes rendas. A atração da demanda implica, pois, a oferta do bem com tais atributos, os quais representam os valores de uso do imóvel, bem como um ativo da economia familiar, e sua aquisição levará em consideração a sua valorização futura na estrutura de preços imobiliários na cidade.

Todavia, o que se observa comumente é que a mensuração do bem habitação, independente do fim a que se destina, geralmente despreza alguns itens de relevante importância no processo de maximização de utilidade do consumidor. As avaliações de imóveis não são elaboradas tomando-se por base o conjunto de características extrínsecas e intrínsecas pertinentes a cada ativo, ficando restritas à análise maior das características físicas do imóvel (BALARINE, 1997). A Fundação Instituto Brasileiro de Geografia e Estatística (FIBGE), em sua Síntese de Indicadores Sociais 2002 (2003, p. 143), para a análise das condições de habitação, textualiza: "[...] a área construída do domicílio, o número médio de pessoas por domicílio e dormitório, o acesso à água e ao esgotamento sanitário, o estado de conservação e a condição de ocupação são, em linhas gerais, indicadores mais eficazes do nível de bem-estar das moradias do que propriamente o tipo de material utilizado na construção do domicílio".

Outras variáveis microeconômicas, de características comportamentais essencialmente do consumidor, contribuem significativamente na formação do preço de habitação. É na caracterização do comportamento da demanda por esse tipo de ativo e na investigação das principais características imobiliárias procuradas que reside a proposta mister do presente artigo. Aliada à importância do tema em estudo, espera-se contribuir com o entendimento de um novo conjunto de inter-relações e fenômenos observados em um mercado habitacional do espaço urbano. Ressalve-se, todavia, que esse mercado habitacional, por sua vez, pode ser definido como espaço geográfico de unidades residenciais/não residenciais e de terras urbanas influenciado pelos mesmos determinantes econômicos. 
Esse agregado pode ser um aglomerado ou mesmo uma cidade, desde que situada de forma isolada no espaço (DIPASQUALE; WHEATON, 1994).

O objeto de estudo aqui selecionado é uma cidade brasileira de porte médio - Fortaleza, Estado do Ceará, cuja escolha permitirá estender as conclusões às principais cidades brasileiras de porte similar. A análise será fundamentada em trabalho seminal desenvolvido por Rosen (1974), onde se define que uma classe de produtos diferenciados pode ser descrita completamente por um vetor de características objetivamente medidas, sendo que os quantitativos das características associadas a cada produto geram os denominados preços hedônicos, definindo decisões locacionais no consumidor. Entretanto, o artigo adiciona à literatura análise especial no tocante à existência de agentes investidores de imóveis, propensos a observar e precificar as características de risco inerentes aos ativos imobiliários.

Na seqüência da estrutura do artigo, a próxima seção trata da caracterização e modelagem de preços hedônicos do bem habitação no espaço urbano, seguida pela abordagem metodológica adotada. Finalizando, na última seção são descritos os resultados empíricos, seguidos pelas conclusões.

\section{MERCADO HABITACIONAL: CARACTERIZAÇÃo E PREÇOS HEDÔNICOS}

O estudo do fenômeno da habitação nasce a partir dos clássicos trabalhos datados do século XIX, de Von Thunen e Schwabe, que realizaram as primeiras pesquisas relacionando valores da terra e aluguéis. É o início da relação do bem habitação com sua variável fundamental: a localização determinando a renda fundiária urbana. Partindo desse prisma, tem-se o início do problema de maximização da renda fundiária urbana (FERREIRA; LEMOS, 2001). Surgido, então, como um problema de localização espacial, Alonso (1964) sedimenta o conceito de acessibilidade ao centro de negócios de determinada área urbana, fundamental no estudo do bem habitação.

O bem habitação detém características acentuadamente específicas e a comum avaliação de imóveis é a tradução do valor que o ser humano lhe atribui. Com efeito, o valor do imóvel é dedutível a partir de uma avaliação direta do bem, de uma avaliação do que aquele bem pode produzir de resultados, ou do simples preço de equilíbrio entre oferta e demanda (DANTAS, 1998). Entre os métodos de avaliação, destaca-se procedimento de comparação do imóvel, avaliando com unidades semelhantes disponíveis no mercado em relação às suas várias características extrínsecas e intrínsecas.

A avaliação da habitação pressupõe identificação das variáveis que influenciam na formação do preço. Cada característica, então, é uma variável a ser investigada, como aspecto observável de um fenômeno e apresentando variações ou diferenças em relação ao mesmo ou a outros fenômenos (DANTAS, 1998).

\subsection{Modelo de preços hedônicos}

A função de demanda imobiliária tem como um dos principais componentes o preço, acerca do qual a literatura de economia urbana centra suas investigações. Para Lucena (1985), o bem ha- 
bitação é decomposto em uma quantidade finita de categorias, da qual se deriva utilidade. Para o autor, o preço final de cada característica dependerá do nível de demanda pela mesma. A dinâmica no composto entre renda e preferências individuais, segundo o autor, levaria os indivíduos a comporem seus estoques individuais.

A abordagem dos preços hedônicos ou preços implícitos deriva da contribuição inicialmente oferecida por Lancaster (1966), o qual afirmou que as intrínsecas características que fazem de um bem particularmente diferente de outro estavam omitidas da teoria. Para o autor, os bens são medidos pelas características que se mostram relevantes para a escolha das pessoas, e o consumidor exerce preferências, maximizando utilidade. $\mathrm{O}$ autor conclui que os bens possuem a eles intrínsecos, ou podem oferecer, múltiplas características em proporções fixas, e são essas características, não os produtos em si, que geram preferências nos consumidores.

Porém, a abordagem de preços hedônicos foi marcada fundamentalmente com o trabalho de Rosen (1974), que fundamenta sua tese em dois pilares básicos: o fato de o produto ser objetivamente medido por um vetor de características e tais preços dos produtos observados, e suas características ou atributos definirem o chamado preço hedônico ou preço implícito. Bens seriam valorados pelo leque de produtos oferecidos, porque essa diferenciação é importante para os agentes e pode ser tratada como um pacote de características e os preços observados podem ser com elas comparados, revelando-se a estrutura da demanda.

O mercado concorrencial, segundo essa teoria, se caracteriza por uma classe de bens que são descritos por $n$ atributos ou características. Os componentes desse vetor são assim medidos como se cada característica fosse avaliada igualmente por cada consumidor. Porém, há diferenças de valoração de cada "pacote de características" por cada agente de mercado. Cada produto possui parcela de participação no preço de mercado e está associado a um valor fixo do vetor $q$, revelando implicitamente uma função $p(q)=p\left(q_{1}, q_{2}, \ldots, q_{n}\right)$ relacionando preços e características. Essa função equivale a uma regressão de preços hedônicos, obtida de pesquisa de comparação entre preços com diferentes características.

O modelo de preços hedônicos, com relação à decisão do consumidor, supõe a existência de um bem com um valor particular do vetor $q$ de características. A função utilidade (estritamente côncava) assume, então, a notação $U\left(c, q_{1}, q_{2}, \ldots, q_{n}\right)$, em que $c$ representa todos os outros bens consumidos e $q$ o vetor de características associadas. A restrição orçamentária do consumidor é dada pela expressão $y=c+p(q)$, a qual restringe a maximização de utilidade do consumidor para a escolha ótima de $c$ e $\left(q_{1}, q_{2}, \ldots, q_{n}\right)$. Formalmente, tem-se a função de otimização:

$$
\operatorname{Max} U(\mathrm{c}, \mathrm{q}) \text {, sujeito a } y=c+p(q)
$$

A condição de primeira ordem do problema de maximização da utilidade acima especificado deriva na relação especificada em (2):

$$
\partial p / \partial q_{i}=P_{i}=U_{q_{i}} / U_{c} \quad i=1,2, \ldots ., n
$$

onde $P_{i}$ é o preço hedônico do atributo $i$ da habitação, sendo que as condições de segunda ordem são satisfeitas, sob hipóteses simples (ROSEN, 1974). 
O problema, porém, requer essencialmente uma contextualização espacial. Nesse sentido, Rosen (1974) define a função dispêndio (bid function) como sendo $\theta\left(q_{1}, q_{2}, \ldots, q_{n} ; u, y\right)$, de acordo com:

$$
U\left(y-\theta, q_{1}, q_{2}, \ldots, q_{n}\right)=u^{*}
$$

onde $u^{*}$ é uma quantidade ótima de nível de utilidade. O consumidor pagará por alternativos valores de $\left(q_{1}, q_{2}, \ldots, q_{n}\right)$ a um nível de utilidade e renda representado por $\theta(q ; u, y)$. Tem-se, então, uma família de curvas de indiferença relacionando a característica $q_{i}$ e o preço pago. Diferenciando a função de utilidade, são obtidas as seguintes relações:

$$
\theta_{q i}=U_{q i} / U_{c}>0, \theta_{u}=-1 / U_{c}<0, e \theta y=1
$$

Para o modelo, $\theta_{q i}$ é a taxa marginal de substituição entre a característica $q_{i}$ e o dinheiro, revelando o preço de reserva da demanda do consumidor por uma porção adicional do vetor de características $q_{i}$. O nível de utilidade é maximizado quando $\theta\left(q^{*} ; u^{*}, y\right)=p\left(q^{*}\right)$ e $\theta_{q i}\left(q^{*} ; u^{*}, y\right)$ $=p i^{*}\left(q^{*}\right), i=1, \ldots, n$, onde $q^{*}$ e $u^{*}$ são as quantidades ótimas. Com efeito, a localização ótima no plano $(q)$ ocorre quando as curvas $p(q)$ e $\theta\left(q^{*} ; u^{*}, y\right)$ se tangenciam, onde dois diferentes consumidores são representados.

A abordagem de Rosen (1974) coincide com a segmentação do mercado concorrencial nos valores dados aos produtos e busca dos mesmos nas especificações a eles inerentes, como resultado do modelo de equilíbrio espacial. Mercados implícitos, portanto, são criados para características como "oferta de serviços públicos”, "acesso a comércio", "quantidade de quartos” etc. As preferências individuais podem compor a função utilidade com a notação $U\left(c_{1}, q_{1}, \ldots, q_{n} ; \alpha\right)$, em que $\alpha$ é o parâmetro que diferencia um consumidor de outro, na vertente de seus gostos individuais. $\mathrm{O}$ equilíbrio dependerá tanto da renda $(y)$, como de $(\alpha)$ e o conjunto das famílias, determinando, nesse ponto, um conjunto de preços implícitos de mercado para a característica $q$.

O modelo proposto por Rosen, por fim, admite a influência de variáveis exógenas da demanda (vetor $Y_{1}$ ) e da oferta (vetor $Y_{2}$ ), sendo que os preços marginais são estimados pela função $F_{i}\left(q, Y_{1}\right)$ para demanda e $G_{i}\left(q, Y_{2}\right)$ para oferta, assumindo a seguinte notação no equilíbrio de mercado, considerando que $i=1, \ldots, n$ e ignorando-se os termos aleatórios:

$$
\begin{aligned}
& p_{i}(q)=F_{i}\left(q_{1}, \ldots, q_{n}, Y_{1}\right) \\
& p_{i}(q)=G_{i}\left(q_{1}, \ldots, q_{n}, Y_{2}\right)
\end{aligned}
$$

onde: $p_{i}=$ preço dos $i$ argumentos; $F_{i}=$ função aos argumentos da demanda; $q_{i}=$ atributo $i$ que compõe determinado bem; $Y_{1}=$ vetor de variáveis exógenas da demanda; $Y_{2}=$ vetor de variáveis exógenas da oferta; $G_{i}=$ função aos argumentos da oferta. Para estimação do modelo, há dois procedimentos sugeridos na literatura. No primeiro, é proposto estimar-se, inicialmente, a equação $p(q)$, sem considerar $Y_{1}$ e $Y_{2}$, calculando-se uma regressão dos preços $P$, conforme os diversos atributos observados, registrando-se a estimação resultante da função $p(q)$ como $\hat{p}(q)$. Os diversos preços implícitos marginais $\partial p(q) / \partial q i=\hat{p}_{i}(q)$ são computados para, finalmente, utilizar-se os preços $\hat{p}_{i}(q)$ como variáveis instrumentais, segundo estágio da estimação simultânea das equações de demanda e oferta. No segundo, estimam-se os preços implícitos apenas em um estágio, buscando impor à forma funcional a maior quantidade possível de variáveis explicativas exógenas, 
alcançando diversos vetores (localização, amenidades físicas, econômicas, financeiras). Optou-se, neste artigo, seguir o segundo procedimento, tanto devido ao foco principal ser a demanda apenas, como pelo que demonstram Brown e Rosen (1982, p. 767): marginal prices constructed only from quantities do not in themselves add any informations to that already provided by observations on quantities. Vários trabalhos na literatura também optam por este procedimento, tais como Lucena (1985), Gonzáles (1993), Cavalcante (2002), Ferreira Neto (2002), Fávero (2003), Hermann (2003), Angelo et al. (2004), Carvalho Jr. e Lemme (2005), Serra e Teixeira (2006).

\section{Aspectos METOdológicos DO MODELO}

\subsection{Equações de preços hedônicos}

Para delimitar a pesquisa na cidade de Fortaleza/CE, considerou-se que somente se habilitariam a serem testadas pelo modelo as observações cujas datas de ocorrência ultrapassavam o marco cronológico convencionado de 01/01/1995 (pós-Real). No total de edificações pesquisadas, foram observadas 4.467 ocorrências, sendo 876 apartamentos residenciais, 1969 flats e 1622 salas comerciais. O alcance da pesquisa no comportamento do mercado de edificações se mostra significativo, incluindo 41 dos 112 bairros da cidade.

A viabilização para a montagem da base de dados com esta magnitude de observações requereu que as unidades observadas fossem computadas em pontos distintos no tempo, por meio da utilização de dados secundários, os quais são os únicos disponíveis pelas fontes aqui utilizadas. ${ }^{1}$ Assim sendo, os modelos de preços hedônicos a serem estimados seguem a estrutura básica de dados em corte transversal. Essa estrutura em corte transversal decorre principalmente das características associadas ao mercado de ativos em análise, fundamentalmente marcadas pela presença de ciclos longos, essencialmente a carteira aqui selecionada, formada exclusivamente por imóveis novos.

Na presente pesquisa, os dados relativos às características físicas, quer sejam do imóvel, quer sejam do bairro de localização, permanecem imutáveis, enquanto grande parte dos dados econômicos foram integralmente ${ }^{2}$ colhidos do Censo IBGE 2000 ou por meio de pesquisa da oferta de acessibilidades no mesmo período, que guiou igualmente a consulta aos equipamentos urbanos de educação e saúde.

1 Não obstante, há o reconhecimento de que, se tal base fosse disponível na forma de dados em painel, haveria melhor estrutura para a estimação dos modelos.

2 Para essa variável, foi escolhido como proxy dado disponibilizado pela Prefeitura Municipal de Fortaleza referente à renda do chefe de família de cada bairro, referente ao ano de 1991, pois não havia sua disponibilidade segmentada por cada bairro no Censo IBGE 2000. Considerando, então, o marco cronológico, procedeu-se à atualização dos valores vigentes em 1991 até o mês de dezembro/2000, numa tentativa de aproximação da renda média. 
No caso, apenas deslocam-se no período de 1995 a 2003 as transações imobiliárias realizadas, dado básico das inferências conduzidas. Porém, para atenuar o efeitos temporais, aplicou-se individualmente atualizações monetárias das negociações pelo INCC, ${ }^{3}$ amplamente adotado pelo mercado de construção civil para atualização de tabelas de vendas. Ou seja, as negociações realizadas possuem igualmente data unificada de valor monetário.

Considera-se, então, que o critério adotado não macula significativamente os resultados finais diante da avaliação de que o mercado de imóveis passa por ciclos em relação aos seus resultados (BALARINE, 1995, 1997), ciclos estes qualificados como longos, como defendido por Lima Jr. (1993). Para esse autor, cada transação imobiliária estaria espaçada de uma nova por um prazo médio e até longo, não se criando necessariamente um referencial de preços, mas sim uma operação atípica, fazendo com que os preços se movimentem com determinada lentidão. Outras características por ele apontadas como as causas da liquidez restrita dizem respeito ao grande número de unidades por empreendimento e aos prazos lentos e mecanismos complexos de negociação. O’Sullivan (1996), por seu turno, defende que há relativa inelasticidade na oferta de imóveis por longos períodos de tempo, dado que o estoque de imóveis usados predomina e que não haveria estimativa de confiança para a elasticidade de preço da oferta.

Com efeito, considera-se aqui que o conjunto de transações realizadas integram em termos temporais um mesmo ciclo de negócios e tendências, não havendo fatores evolutivos significativos que justificassem a inclusão de variáveis de tempo entre o período 1995 a 2003, notadamente marcado pela maturação da estabilidade econômica alcançada pelo País após a divulgação do plano Real (1994). A análise retrospectiva do preço médio do metro quadrado de Fortaleza, para o período de 1995 a 2003, referente a todas as transações de imóveis edificados realizadas, quando trazidas monetariamente a uma mesma data, poderia ilustrar a existência do ciclo, como se observa no Gráfico 1.

3 Índice Nacional de Custo da Construção (INCC). É um dos três itens que compõem o Índice Geral de Preços (IGP), representando $10 \%$ do índice. O INCC é calculado entre o primeiro e o último dia do mês civil. 


\section{Gráfico 1 - Evolução do preço médio do metro quadrado mercado imobiliário de Fortaleza}

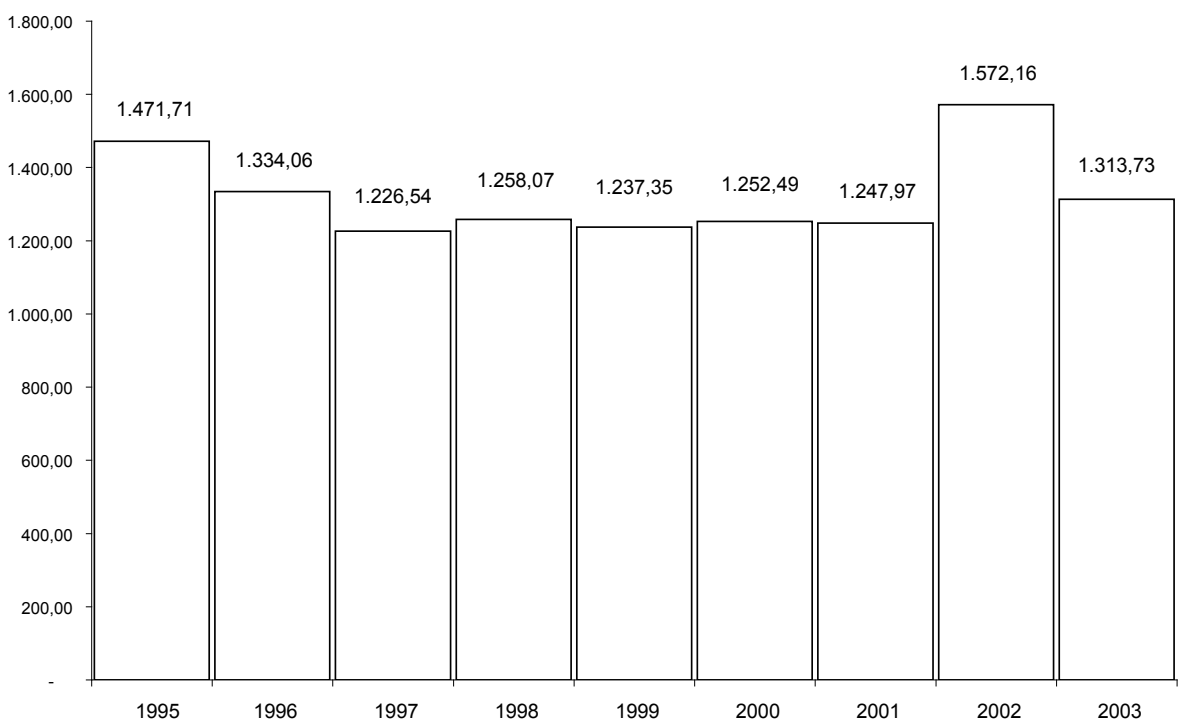

Fonte: Elaboração dos autores, a partir de dados do SECOVI.

Assim, como se detalha adiante, os preços marginais são estimados apenas na ótica da demanda, ou seja, somente em um estágio (BROWN; ROSEN, 1982). Os dados utilizados referem-se a transações efetivamente realizadas e destaca-se o alcance das variáveis explicativas incorporadas no processo de modelagem. Essa peculiar condição aqui utilizada tenciona inclusive evitar ocorrências de problemas de autocorrelação espacial, que é um risco alertado por Dantas (2003). De acordo com Furtado e Ruiz (2006), porém, a boa determinação ou discriminação da vizinhança do imóvel torna desnecessária a utilização do modelo espacial.

No processo de seleção dos imóveis, buscou-se identificar entre os macrosegmentos (residencial, comercial e terrenos), os componentes mais representativos. Kullmann (2003, p. 15) ressalta a importância da distinção entre essas categorias de imóveis, ao expressar que [...] empirical evidence shows that these are different asset classes that are only weakly correlated with each other and respond to different economic forces, enquanto Cruz e Santos (2000) afirmam que os fatores que influenciam os mercados de habitação residencial e não residencial são distintos na ótica da oferta e da demanda.

Os terrenos mereceram um tratamento especial, em razão da inexistência de registros pertinentes a esse segmento no SECOVI, sendo reutilizado banco de dados tabulado por Sousa Filho (2002), colhido por meio de pesquisa primária e constituído pelas ofertas de terrenos em anúncios classificados de periódicos locais no período de 1995 a 1998. As ocorrências classificadas como terrenos totalizaram 539 registros, alcançando 70 bairros da cidade. 


\section{Gráfico 2 - Evolução do preço médio do metro quadrado de apartamentos nos principais bairros de Fortaleza}

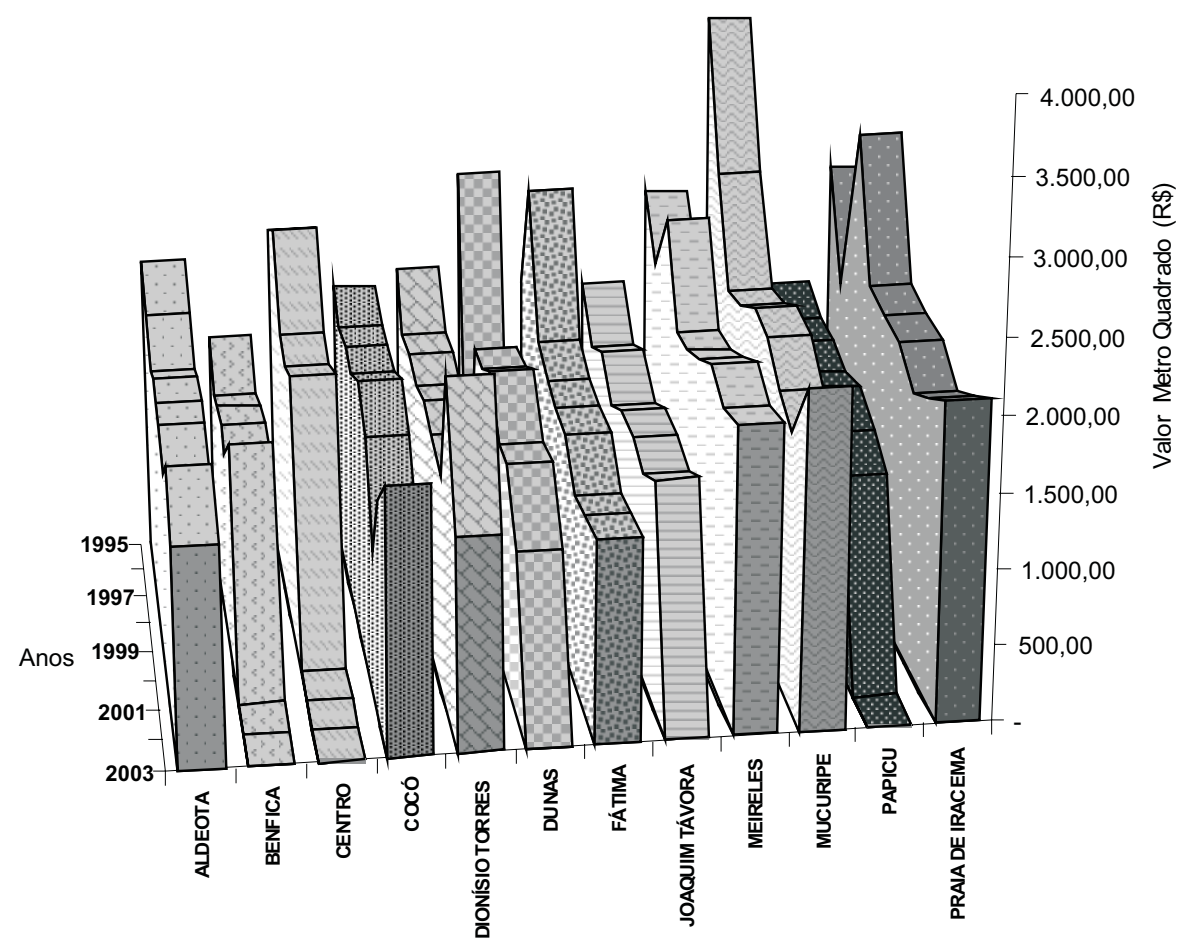

Fonte: Elaboração dos autores, a partir de dados do SECOVI.

Quanto à definição das variáveis de influência, admitiu-se que existe extrapolação de variáveis físicas, destacando-se a presença das características locacionais como igualmente determinantes. Tais características incorporariam a medida de um elemento clássico em modelagem de economia urbana: o consumo de acessibilidade. As amenidades ou atrativos, assim denominados, sempre estarão incorporados no valor dos bens (CHESHIRE; SHEPPARD, 1995).

Os modelos propostos foram fragmentados de acordo com os segmentos imobiliários específicos do novo estoque habitacional, prática observada em Ferreira Neto (2002) e em Cavalcante (2002). As variáveis selecionadas foram:

Características físicas: as variáveis físicas têm cientificamente se mostrado como vetor significante para explicar o preço da habitação. Foram selecionados aqui os seguintes indicadores: área privativa $\left(\mathrm{m}^{2}\right)$, quantidade total de unidades, quantidade de blocos, quantidade de apartamentos por pavimento e quantidade total de pavimentos. Tais variáveis foram utilizadas por Ferreira Neto (2002), Lucena (1985), Dantas (2003) e Rosiers e Thérriault (1996). Os dados foram colhidos no SECOVI, sendo aqui desprezados indicadores reconhecidamente importantes, como elevadores, quartos e vagas de garagem, em virtude de indícios de inconsistência nos registros do SECOVI, porém, admitindo-se parcialmente sua influência na variável-chave área. A variável idade do imóvel não foi avaliada, em virtude de a amostra restringir-se ao novo estoque imobiliário. 
Renda: Lucena (1985) afirma que há suposições de que o indivíduo pondera com bastante relevância os aspectos de vizinhança, dispondo-se a pagar mais para se localizar em um local com padrão de renda mais elevado. Balarine (1995) defende que o nível de renda desempenha papel preponderante na composição do estoque habitacional. Para essa variável, foi aqui escolhida como proxy a renda do chefe de família de cada bairro, do ano de 1991 corrigido para o ano 2000 pelo IGP-DI, dado este disponibilizado pela prefeitura municipal. Tal escolha deu-se em virtude de o Censo 2000 da FIBGE não disponibilizar esse indicador de maneira objetiva, como necessário às estimações.

Consumo de acessibilidades: a interação com a vizinhança faz parte do cotidiano, de tal forma que os atributos da vizinhança afetam a constituição pessoal e a acumulação de capital econômico. Essa interação das pessoas com o ambiente tem sido um dos principais pontos de investigação por parte da abordagem dos preços hedônicos (BAJARI; KAHN, 2003). O conjunto de amenidades ou consumo de acessibilidades foi aqui segmentado em acessibilidade, educação, saúde e lazer. O valor encontrado para cada bairro (quantidade de equipamentos urbanos) é ponderado pela população do bairro e, no caso das escolas, esse número é substituído para a população com idade inferior a 19 anos. Em virtude de dificuldade de especificação de localização correta do equipamento urbano, foi criado aqui critério especial de compartilhamento, visando eliminar eventuais distorções. Sua composição pesquisa existência de equipamentos urbanos nos vetores de acessibilidade (supermercados, farmácias, padarias, postos de gasolina, agências bancárias e shopping centers), educação (escolas públicas ou particulares), saúde (hospitais públicos e particulares, casas de saúde, postos de saúde e clínicas) e lazer (restaurantes, bares, barracas, cafés, lancheterias, pizzarias, churrascarias, galeterias, cinemas, teatros, casas de espetáculo, clubes, estádios e boates).

Distância ao centro de negócios: na literatura econômica sobre tema similar, a variável Distância ao Centro é constantemente evocada, tendo se mostrado como uma das mais significativas. De acordo com Ferreira e Lemos (2001), as variáveis-chave que explicam a alocação de atividade econômica no entorno do núcleo urbano são a renda fundiária e os custos de transporte. Para Lucena (1985), o processo de crescimento das cidades fez com que áreas mais antigas se localizassem em torno do Centro de Negócios. Atualmente, como se evidencia o fenômeno do multicentrismo na cidade de Fortaleza, podem ser considerados centros de negócios o Centro Tradicional e o Centro Nobre (referente ao grande bairro da Aldeota), região de elevada renda da cidade. Com efeito, para fins de construção dessa variável explicativa, as distâncias de cada bairro foram aqui obtidas pela medida de uma linha reta no mapa cartográfico da cidade com escala, ligando-se o centro de cada bairro a dois pontos de referência nos respectivos centros de negócios.

Segurança: Andrade e Rondon (2002) afirmam que a criminalidade afeta diretamente o bem-estar dos indivíduos, após encontrarem fortes evidências empíricas de que as taxas de crime afetam significativamente o valor dos aluguéis. Os autores reputam ao tema importância especial, em virtude da mensuração do custo indireto imposto ao indivíduo pela criminalidade. Ainda de acordo com esses autores, existe um custo econômico relativo à perda de produção e renda por parte das vítimas. São os chamados custos sociais impostos à sociedade, que reduzem o bem-estar agregado. Buscando mensurar o custo econômico da criminalidade imposto ao indivíduo nos preços dos imóveis, foi realizada consulta ao Centro Integrado de Operações de Segurança do Estado do Ceará (CIOPS) para construção dessa variável explicativa, a qual forneceu, para os anos de 2002 e 2003, o único indicador setorizado por bairro, dado pela quantidade de homicídios por cada bairro oficial da cidade, ponderada pela população do bairro.

Densidade e verticalização: a presença de altos índices de verticalização resulta em dois aspectos 
negativos: o indício de alta concentração populacional e impacto ambiental no nível de ventilação do bairro. A construção dessa variável explicativa utilizou a área de cada bairro, em hectare, informada pela Secretaria Municipal de Infra-Estrutura e Controle Urbano da Cidade de Fortaleza (SEINF), sendo calculada a razão entre a quantidade de domicílios ou pessoas, conforme o caso, e essa área. Para verticalização, foi colhido no IBGE dado de índice de residências do tipo "apartamento" por cada bairro oficial.

Saneamento e limpeza urbana: os dados de saneamento foram colhidos na Empresa Estatal de Águas e Esgotos, no período de 1995 a 2003, enquanto que a análise das condições de limpeza foi colhida no Censo do IBGE (ano 2000) e representada pelo índice de domicílios atendido por coleta de lixo domiciliar.

Variáveis qualitativas: foram incluídas ainda três variáveis qualitativas binárias para verificar se o imóvel está situado em corredor comercial, localiza-se em área nobre ou se o bairro possui amenidades, representadas pela existência de praias.

Custo de oportunidade de capital ajustado ao risco: incorporação de um novo vetor de determinantes para um tipo especial de demandante, o investidor, que observa aspectos de risco, medido em paralelo pelo Modelo de Determinação de Preços dos Ativos de Capital (CAPM), cuja notação final aqui utilizada obedeceu à notação:

$$
r_{i=} r_{f}+\beta_{i a}\left(r_{m}-r_{f}\right)
$$

onde: $r_{i}=$ retorno do bairro $i$ ajustado ao risco ou custo de oportunidade de capital; $r_{f}=$ retorno médio de um título de renda fixa; $\beta_{l a}=$ beta ou nível de risco associado ao bairro $i ; r_{m}=$ retorno médio da carteira de mercado.

O coeficiente Beta da equação é calculado pelo crescimento esperado do valor patrimonial, ou seja, como o preço se comporta em relação ao mercado, como admitido por Damodaran (1997) e Brealey e Myers (1992). O mercado na análise é formado pelo conjunto de todas as negociações de imóveis novos registradas pelo SECOVI (período de 1995 a 2000) e o metro quadrado construído de cada bairro é uma opção de aplicação. O retorno do bairro é calculado pela variação do preço médio do metro quadrado de cada bairro analisado mensalmente.

Vacância: a vacância é traduzida pela proporção dos imóveis vagos no estoque total, sendo esperado que o preço da habitação varie inversamente em relação ao nível de vacância. O aluguel estaria indiretamente captado pela medição do nível de vacância no bairro urbano, pois há fortes evidências empíricas de que as taxas de vacância e as de tributos sobre a propriedade afetam significativamente o preço dos serviços habitacionais (SMITH, 1974).

A influência da vacância na taxa dos aluguéis foi evidenciada por estudo conduzido por Webb e Fisher (1996). Para Damodaran (1997), a alta concorrência eleva o desempenho dos aluguéis, elevando, portanto, o valor atual do imóvel. Rosiers e Thériault (1995), por sua vez, identificaram o fenômeno da vacância como variável explicativa em estudo de preços hedônicos.

O presente estudo buscou uma aproximação da medida de imóveis desocupados por bairro por meio do cruzamento da quantidade de domicílios existentes e da quantidade de domicílios particulares permanentes recenseadas pelo IBGE (Censo de 2000), assumindo-se a hipótese de que a diferença encontrada representaria uma aproximação da quantidade de imóveis vagos. Dessa forma, formatou-se e construiu-se uma matriz de dados em corte transversal para esse ciclo de nove anos 
do mercado imobiliário da cidade Fortaleza, confrontando os preços atualizados de cada transação imobiliária com cada característica observada a ele associada, de forma a se obter a perspectiva hedônica: o imóvel seria composto de um conjunto de componentes individuais, sendo que cada um deteria o seu preço implícito. O valor de mercado de imóveis decorre, pois, de vetores de características físicas, locacionais, econômicas e financeiras, cada um com suas componentes individuais (O’SULLIVAN, 1996), como aqui demonstrados na Figura 1.

Figura 1 - Modelo econômico-financeiro de preços hedônicos: estruturação da matriz de dados

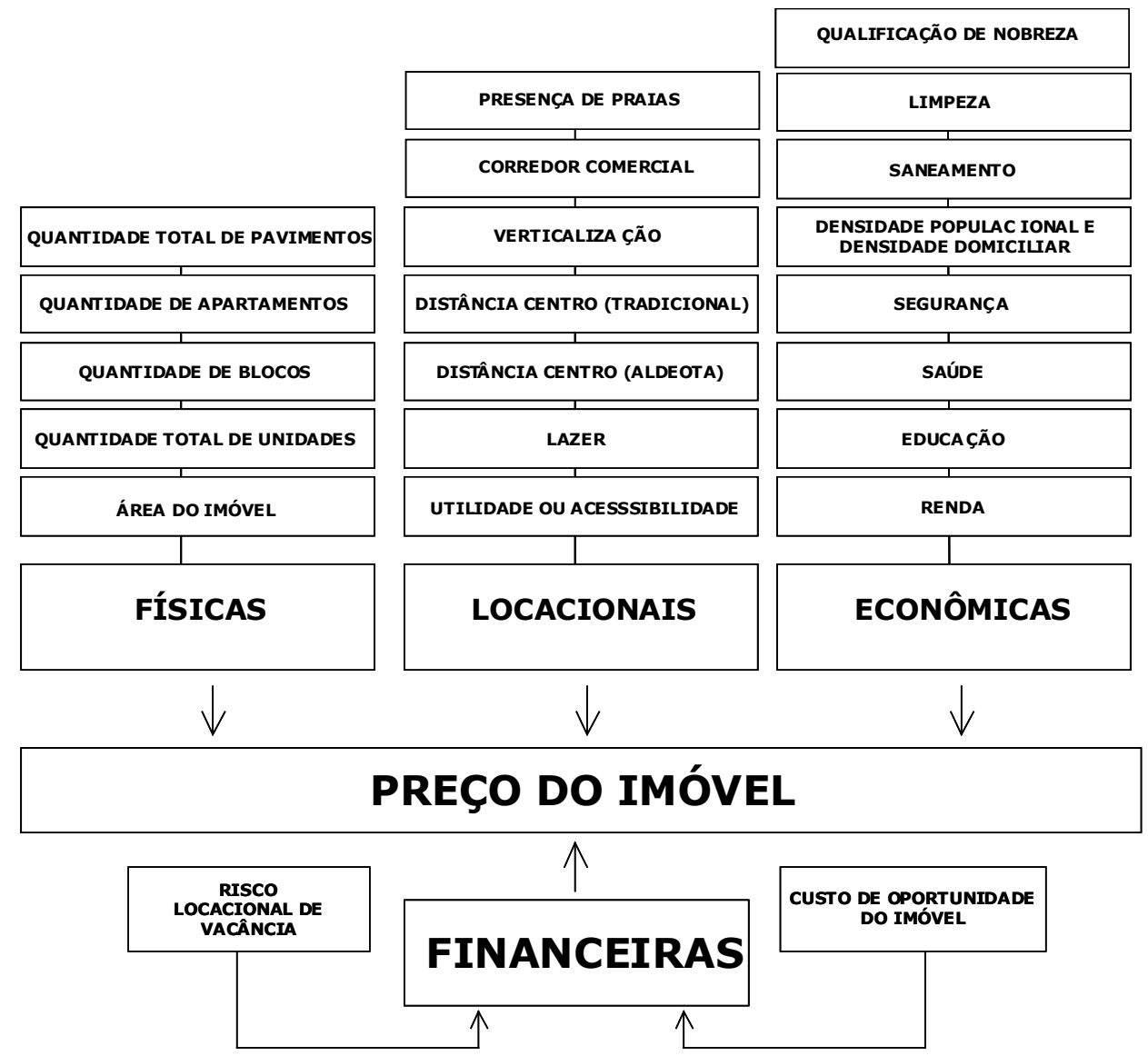

Fonte: Elaboração dos autores. 


\section{RESUltados}

O modelo de preços hedônicos foi especificado por meio da forma funcional semi-log, ${ }^{4}$ escolha esta devido à melhor adequação de ajustamento, e à sugestão e aplicação por parte de outros autores, tais como, Ekeland et al. (2002), Angelo et al. (2004). Para estimação, foi utilizado o método dos mínimos quadrados com erro robusto, seguindo o procedimento de White para correção de heterocedasticidade.

A estimação foi efetuada da forma irrestrita para a restrita, como aplicado por Ferreira Neto (2002), a partir de Ramanathan (1995), o qual indica como uma metodologia de determinação do modelo iniciar-se de um modelo geral (irrestrito) e então gradativamente reduzi-lo, eliminando variáveis com coeficientes estatisticamente não significantes. Ainda segundo o autor, o processo permite ao pesquisador a utilização de teorias econômicas aliadas à intuição e ao conhecimento do tema, resultando numa especificação parcimoniosa e mais simples.

As Tabelas 2, 4, 6 e 8 apresentam os resultados das apurações individuais finais realizadas para o modelo, antecedidas pelas conclusões atribuíveis a cada segmento estudado e pelas Tabelas $1,3,5$ e 7, que apresentam estatísticas descritivas das variáveis apontadas como relevantes.

Apartamentos (Tabela 2). De acordo com os resultados encontrados, há indicação de que, embora o comprador de apartamentos pareça não se preocupar com a quantidade total de unidades no empreendimento, cujo efeito marginal positivo sobre o preço é de apenas $0,038 \%$, comprova-se importância principalmente em relação à área, à quantidade total de blocos e à quantidade de apartamentos por pavimento, cujos efeitos marginais sobre a variação de preço decorrentes do acréscimo de uma unidade adicional são de $0,64 \%,-5,08 \%$ e $-3,84 \%$, respectivamente. A concentração de unidades, quando excessiva, reduz o bem-estar por externalidades negativas, atuando negativamente no preço do imóvel. O resultado permeado pela busca de elevadas metragens se mostra compatível com os estudos de Fávero (2003), Ferreira Neto (2002), Cavalcante (2002) e Dantas (2003), sendo que este último identifica ainda a restrição a grandes conjuntos habitacionais por parte dos consumidores, que se revela consonante com o sinal encontrado para a variável quantidade de blocos.

A aparente restrição à quantidade excessiva de blocos por empreendimento pode denotar preocupação com qualidade da vizinhança e menor disposição a excessos no processo econômico de valoração da renda fundiária urbana relacionada ao fator terra. O nível de lazer do bairro de localização do imóvel possui acentuada importância. Isso talvez porque crie percepção de que o local escolhido permite maximização de bem-estar em horas não-laborativas, denotando essencialmente qualidade da vizinhança e nível de relacionamento social daquela comunidade. A relação do consumidor com o item lazer é demonstrada igualmente incorporando-se variáveis estruturais do prédio (piscina, quadras, salão de festas, jardins, terraço, entre outros) não contempladas no presente estudo, mas apontadas por Fávero (2003) como vetor de atributos com significativa importância na formação de preços de imóveis residenciais. Os resultados para o

4 Isso significa que o modelo estimado segue a seguinte especificação: $\ln p_{i}=x_{i}^{\prime} \beta+\varepsilon_{i}$, onde o efeito de uma variável de controle $\left(x_{k}\right)$ sobre o preço do imóvel $\left(p_{i}\right)$ é dado por, $\left(\partial p_{i} / p_{i}\right) / \partial x_{k}=\beta_{k}$. Ou seja, os coeficientes estimados representam os efeitos marginais das variáveis respectivas sobre a taxa de variação dos preços dos imóveis.

5 Não obstante, foram estimadas outras especificações dos modelos a fim de garantir maior robustez às estimativas aqui apresentadas. No Anexo estão reportadas tais estimações, as quais incluem apenas as variáveis cujos coeficientes mostraram-se estatisticamente significantes. 
item lazer da estrutura predial são ainda avaliados como relevantes em Ferreira Neto (2002), Maurer et al. (2004) e Gonzales (1993).

Na escolha dos apartamentos, a distância ao centro nobre, o qual tem substituído o antigo núcleo central da cidade, detém importância na formação dos preços dos imóveis. A distância ao centro e aos respectivos subcentros comerciais se mostra amplamente significativa em abordagens de preços hedônicos, como demonstram Lucena (1985), Gonzales (1993), Rosiers e Thériault (1996), Ferreira Neto (2002), Dantas (2003) e Hermann (2003).

O modelo indica que não há preocupação com o quadro de verticalização do bairro nos preços, o que hoje gera problemas urbanos de alta concentração populacional e externalidades ambientais (poluição, nível de ventilação). A variável verticalização, porém, buscando captar uso excessivo do solo, de acordo com Haddad e Hermann (2003), possui problemas de endogeneidade, pois o preço da terra condiciona o tipo de construção e, dessa forma, zonas mais valorizadas tendem a ser mais verticalizadas.

Somente na ótica de utilização de apartamentos estritamente para consumo final, o consumidor parece não conferir importância à presença massiva de rede de equipamentos urbanos de comércio no bairro, provavelmente por aceitar o processo de aglomerações centrais. Ou seja, a unidade residencial, então, buscaria orbitar tal região, por meio da conciliação da facilidade no consumo de amenidades e, em caráter predominante, a tranqüilidade na habitação residencial. O nível de acessibilidade, portanto, seria resultado do grau de utilização residencial do fator terra e não o inverso. Esse resultado convergiu com o de Haddad e Hermann (2003), o qual revelou como melhor estimativa de qualidade ambiental o coeficiente arbóreo do bairro e presença em zona residencial. Nesse sentido, Fávero (2003) também conclui que a presença de shopping center (um dos principais componentes do vetor de acessibilidade), não possui importância significativa na formação dos preços imobiliários de baixa e alta renda, diferentemente da importância de parques e áreas verdes que aliam lazer a amenidades ambientais. As zonas estritamente residenciais geram aprazibilidade e criam ambientes de tranqüilidade aos moradores (HERMANN, 2003). Cavalcante (2002) e Ferreira Neto (2002) apontam que a rejeição a fatores de externalidades negativas supera o benefício da acessibilidade para que os consumidores fixem residência. $\mathrm{O}$ instigante e preliminar resultado do grau de acessibilidade também é encontrado por Lucena (1985), o qual afirma que o nível de acesso aos centros mede indiretamente os serviços de comércio demandados, independente do bairro.

Quanto à localização, as estimativas também indicam que o consumidor prefere estabelecer-se na menor distância do centro nobre de comércio e substitui o centro tradicional por um vetor de acessibilidades a serviços. Miranda e Domingues (2007), por seu turno, combinam acessos a serviços, comércio e lazer, e concluem que os consumidores de Belo Horizonte dão preferência significante a esses fatores, em detrimento de suas escolhas por moradias mais distantes do local do trabalho. Os resultados de acessibilidade convergem ainda com conclusões de Haddad e Hermann (2003), Andrade e Rondon (2002) e Ferreira Neto (2002). A oferta de acessibilidade evita a atração por outras regiões, e esse novo caso é que atrai os anéis de consumo imobiliários. De acordo com Haddad e Hermann (2003), modelos que incluem fatores de acessibilidade revelam a influência da oferta de infra-estrutura urbana sobre a moradia, tendendo a valorizar esses locais. 
A variável segurança mostrou-se com relevante participação na formação de preços e com os sinais esperados, ou seja, reduzindo os preços dos imóveis. Seu efeito marginal, na média, provocaria uma redução de 3,17\% no preço do apartamento. Haddad e Hermann (2003) encontraram influência de segurança nos preços de imóveis residenciais paulistas a partir da taxa de homicídio por 100 mil habitantes, enquanto Andrade e Rondon (2002) revelaram igualmente que a taxa de homicídios do bairro influenciava os preços dos aluguéis da cidade de Belo Horizonte. Ferreira Neto (2002) utilizou vários indicadores de segurança, todos ponderados pela população (homicídios, roubo a veículos, pessoas, ônibus e casas, apreensão de drogas e prisão). $\mathrm{O}$ autor encontrou sinais negativos e significância de todas as variáveis empregadas, à exceção do roubo a pessoas, esse atribuído à questão da renda do bairro. Serra e Teixeira (2006), utilizando a taxa de homicídios, comprovaram que a mesma impacta de forma significativa o valor de locação dos apartamentos da cidade de Curitiba, e Carvalho Jr. e Lemme (2005) observaram que o aumento de crimes, medidos por assassinatos, resulta em decréscimo do preço dos imóveis residenciais no bairro da Tijuca, cidade do Rio de Janeiro. Com efeito similar, Gonzáles (1993) captou a influência negativa da segurança segundo a proximidade de favelas em aluguéis de bairros da cidade de Porto Alegre.

A oferta localizada de saúde e escolas atua negativamente nos preços, indicando provavelmente que existe preocupação com externalidades: elevado tráfego de carros, poluição sonora e ambiental (lixo hospitalar) ou primazia da qualidade em relação à quantidade. $\mathrm{O}$ sinal negativo encontrado para hospitais converge com os resultados de estudo de Fávero (2003) e, no caso de escolas, corresponde ao mesmo efeito encontrado por Ferreira Neto (2002). O sinal negativo presente em coleta domiciliar confronta a teoria, mas também pode revelar que existe preocupação com as externalidades dessa coleta (mau cheiro e depósitos), ou correlação com perfil de ocupação que gera esse índice de coleta, notadamente aglomerações residenciais de baixo poder aquisitivo.

Tabela 1 - Estatística descritiva por características das variáveis de controle apartamentos

\begin{tabular}{lcccccccc}
\hline & Área & Unidades & Apto. Pav. & Blocos & Distância C. Nobre & Acessibilidade & Lazer & Coleta \\
\hline Média & 122.57 & 56.52 & 2.97 & 1.38 & 2.15 & $4.60 \mathrm{E}-05$ & 0.0029 & 0.9327 \\
Mediana & 120.00 & 34.00 & 2.00 & 1.00 & 1.26 & 0.0000 & 0.0035 & 0.9469 \\
Máximo & 395.00 & 684.00 & 12.00 & 10.00 & 10.08 & 0.0100 & 0.0147 & 0.9969 \\
Mínimo & 32.00 & 6.00 & 1.00 & 1.00 & 0.00 & 0.0000 & 0.0000 & 0.0980 \\
Desvio padrão & 62.04 & 77.88 & 1.95 & 1.29 & 2.33 & 0.0007 & 0.0024 & 0.0916 \\
\hline
\end{tabular}




\begin{tabular}{lccccccc}
\hline & $\begin{array}{c}\text { Densidade } \\
\text { Domicílios }\end{array}$ & $\begin{array}{c}\text { Densidade } \\
\text { População }\end{array}$ & $\begin{array}{c}\text { Oferta de } \\
\text { Saúde }\end{array}$ & $\begin{array}{c}\text { Oferta de } \\
\text { Segurança }\end{array}$ & $\begin{array}{c}\text { Oferta de } \\
\text { Escolas }\end{array}$ & $\begin{array}{c}\text { Nível de } \\
\text { Vacância }\end{array}$ & Risco \\
\hline Média & 30.78 & 90.5724 & 0.0020 & 0.0001 & 0.0021 & 0.1418 & 1.8679 \\
Mediana & 33.00 & 98.0000 & 0.0029 & 0.0001 & 0.0022 & 0.1000 & 1.9359 \\
Máximo & 67.00 & 233.0000 & 0.0048 & 0.0006 & 0.0079 & 1.0000 & 2.3799 \\
Mínimo & 1.000 & 3.0000 & 0.0000 & 0.0000 & 0.0000 & 0.0000 & 1.1975 \\
Desvio padrão & 13.42 & 36.688 & 0.0012 & 0.0001 & 0.0015 & 0.1379 & 0.2727 \\
\hline
\end{tabular}

Fonte: Elaboração própria.

Embora sejam pouco abordadas na literatura, as características financeiras, denotadas pela vacância e risco, tiveram seus resultados de acordo com o esperado, haja vista que ambas detiveram efeitos negativos, apresentando, no caso de risco, efeito marginal de 1,4\% na redução de preço, decorrente de um aumento de $10 \%$ no custo de oportunidade de capital. Tais resultados foram similares aos encontrados por Rosiers e Thériault (1996) para o mercado imobiliário americano. A ocorrência do quadro de vacância em um mercado imobiliário implica a maior probabilidade de quebra de fluxos de receitas. Dessa forma, é natural que os mesmos sejam negativamente precificados pelos investidores. Igualmente, a análise desse agente tem como insumo básico o valor presente dos fluxos geráveis por um investimento, sendo, nesse sentido, de fundamental importância o custo de oportunidade de capital ou risco associado ao investimento, ou seja, a que taxa ele deverá trazer os fluxos líquidos. Assim, maximizada a taxa, a qual embute o risco imobiliário associado, menos atrativo será o imóvel, sendo esperado o sinal negativo do coeficiente.

Cabe finalmente frisar que, dentre as características econômicas, a variável renda foi excluída do modelo, tanto por apresentar sinal negativo como por se mostrar sem significância estatística, não obstante seja apontada como significativa pela maioria dos textos da literatura. Outros trabalhos, por exemplo, Haddad e Hermann (2003), optam por excluir a renda do modelo de preços hedônicos, uma vez que a consideram endógena, ou seja, o preço do imóvel também explicaria a renda. Dos resultados aqui apresentados, há de se considerar, todavia, a utilização da única proxy disponível utilizada, que possui defasagem temporal acentuada (ano base 1991). 
Tabela 2 - Estimativas da equação de preço para apartamentos classificadas por características das variáveis de controle

\begin{tabular}{|c|c|}
\hline Variáveis por Características & Coeficientes \\
\hline Constante & $12.799^{*}$ \\
\hline \multicolumn{2}{|l|}{ CARACTERÍSTICAS FÍSICAS } \\
\hline Áea do imóvel & $\begin{array}{c}0.0064^{*} \\
(0.0003)\end{array}$ \\
\hline Unidades totais prédio & $\begin{array}{c}0.00038^{*} \\
(0.0001)\end{array}$ \\
\hline Apto. por pavimento & $\begin{array}{l}-0.0384^{*} \\
(0.0105)\end{array}$ \\
\hline Qtde. de blocos & $\begin{array}{l}-0.0508^{*} \\
(0.0091)\end{array}$ \\
\hline \multicolumn{2}{|l|}{ CARACTERÍSTICAS LOCACIONAIS } \\
\hline Distância Centro Nobre & $\begin{array}{l}-0.1034^{*} \\
(0.0086)\end{array}$ \\
\hline Acessibilidade & $\begin{array}{r}35.232^{*} \\
(10.6940)\end{array}$ \\
\hline Lazer & $\begin{array}{c}23.613^{*} \\
(6.6685)\end{array}$ \\
\hline \multicolumn{2}{|l|}{ CARACTERÍSTICAS ECONÔMICAS } \\
\hline Acesso à coleta & $\begin{array}{l}-0.7658^{*} \\
(0.1437)\end{array}$ \\
\hline Densidade domiciliar & $\begin{array}{l}-0.0199^{*} \\
(0.0060)\end{array}$ \\
\hline Densidade populacional & $\begin{array}{c}0.0067^{*} \\
(0.0021)\end{array}$ \\
\hline Saúde & $\begin{array}{r}-60.659^{*} \\
(13.7586)\end{array}$ \\
\hline Seguranca & $\begin{array}{c}-317.34^{* \star} \\
(128.6121)\end{array}$ \\
\hline Oferta de escolas & $\begin{array}{r}-25.666^{*} \\
(10.5764)\end{array}$ \\
\hline \multicolumn{2}{|l|}{ CARACTERÍSTICAS FINANCEIRAS } \\
\hline Nível de vacância & $\begin{array}{l}-0.2886^{\star} \\
(0.1092)\end{array}$ \\
\hline Risco (oportunidade capital) & $\begin{array}{l}-0.1413^{* *} \\
(0.0627) \\
\end{array}$ \\
\hline Observações e estatísticas: & $N=876 ; R^{2}=0,84 ; F=305,7^{\star}$ \\
\hline
\end{tabular}

Nota: Desvios padrão entre parênteses; $\left({ }^{*}\right)$ significante a $0,5 \%$; $(* *)$ significante a $1 \%$.

Fonte: Elaboração própria.

Flats (Tabela 4). As estimativas para flats espelham importância a fatores como tamanho da área interna e gabarito (altura) do prédio, convergindo com resultados de Cavalcante (2002), Dantas (2003) e Ferreira Neto (2002). Observa-se, entretanto, que o efeito marginal da adição de um 
metro quadrado no preço $(2,19 \%)$ é cerca de quatro vezes superior ao efeito observado para apartamento. $\mathrm{O}$ efeito positivo da alta concentração de unidades por pavimentos pode denotar preocupação com custos de ocupação, fato contrário ao observado nos resultados para apartamentos (Tabela 2), não obstante reduzir bem-estar. O consumidor de flats caracteriza-se pela transitoriedade ou investimento: essa condição pode atuar no resultado final do modelo, que desconsidera as características de lazer e acessibilidade, essencialmente ligadas à perpetuidade da moradia e, no caso de estudos anteriores de preços hedônicos, indicadas como possíveis influenciadores no preço. Tal consumidor parece buscar facilidade no acesso aos centros, através da localização em corredores comerciais, porém busca melhor qualidade de vida pagando mais por imóveis mais distantes das regiões centrais. Não parece haver preocupação com aglomerações populacionais/domiciliares e acesso à saúde e a segurança. São importantes economicamente na formação do preço: a limpeza, coadunando com Lucena (1985); o nível de renda, de acordo com a teoria econômica e compatível com trabalhos de Dantas (2003), Fávero (2003) e Lucena (1985); as condições de saneamento, de acordo com o esperado pela teoria e com Lucena (1985) e, por fim, as escolas. Os sinais são aqueles esperados pela teoria e as escolas afastariam o consumo. Não se mostrou importante a oferta localizada de saúde, talvez pelo caráter individual não familiar dessa habitação.

De acordo com Sandberg e Johansson (2001), a procura por flats maiores gera menor custo de ocupação, o que se mostra consonante com os resultados aqui encontrados: significância das variáveis gabarito ou quantidade de pavimentos e unidades por andar, que resultam ambos em menor custo de ocupação. Os autores, por sua vez, encontraram significância em estudo dirigido ao segmento para as variáveis referentes à distância dos centros comerciais, densidade populacional, densidade domiciliar, taxa de turn-over e proximidade às universidades e shoppings.

Tabela 3 - Estatística descritiva por características das variáveis de controle flats

\begin{tabular}{|c|c|c|c|c|c|c|}
\hline & Área & Pavimentos & & Renda & $\begin{array}{l}\text { Distância } \\
\text { C. Nobre }\end{array}$ & $\begin{array}{l}\text { Distância } \\
\text { C.Tradiciona }\end{array}$ \\
\hline Média & 44.97 & 19.27 & & 1194.51 & 1.36 & 2.89 \\
\hline Mediana & 44.00 & 20.00 & & 1550.40 & 0.84 & 2.52 \\
\hline Máximo & 147.00 & 23.00 & & 1550.40 & 3.36 & 5.88 \\
\hline Mínimo & 25.00 & 10.00 & & 126.77 & 0.84 & 1.37 \\
\hline \multirow[t]{2}{*}{ Desvio padrão } & 13.54 & 3.23 & & 431.73 & 0.70 & 1.17 \\
\hline & $\begin{array}{c}\text { Apto. } \\
\text { Pavimento }\end{array}$ & & Coleta & & Saneamento & $\begin{array}{l}\text { Oferta de } \\
\text { Escolas }\end{array}$ \\
\hline Média & 9.40 & & 0.9193 & & 0.7700 & 0.0023 \\
\hline Mediana & 10.00 & & 0.9409 & & 0.7853 & 0.0012 \\
\hline Máximo & 14.00 & & 0.9847 & & 1.8333 & 0.0063 \\
\hline Mínimo & 4.00 & & 0.3879 & & 0.4310 & 0.0000 \\
\hline Desvio padrão & 3.45 & & 0.1210 & & 0.3524 & 0.0020 \\
\hline
\end{tabular}

Fonte: Elaboração própria.

Os resultados do presente estudo indicam que a variável quantidade total de unidades não foi considerada importante, condição atribuível ao fato de que ao flat já está implícita uma elevada 
vizinhança. Também sem relevância foram inferidas as variáveis nobreza do bairro, já possivelmente captada pelo nível de renda, e a presença de praias, coadunando com tese de Lucena (1985), quando discorre a respeito dos bens livres que geram excedente de consumo.

Tabela 4 - Estimativas da equação de preço para flats classificadas por características das variáveis de controle

\begin{tabular}{cc}
\hline Variáveis por Características & Coeficientes \\
\hline Constante & $3.8050^{*}$ \\
CARACTERÍSTICAS FísICAS & $0.0219^{*}$ \\
Área do imóvel & $(0.0009)$ \\
Qtde. de pavimentos & $0.0220^{*}$ \\
Aptos. por pavimento & $(0.0036)$ \\
CARACTERÍSTICAS LOCACIONAIS & $0.0206^{*}$ \\
Distância Centro Nobre & \\
Distância Centro Tradicional & $1.1383^{*}$ \\
Corredor comercial & $(0.2708)$ \\
CARACTERÍSTICAS ECONÔMICAS & $0.1191^{*}$ \\
Acesso à coleta lixo & $(0.0526)$ \\
Ofível de renda & $0.0619^{*}$ \\
\hline Saneamento & $\mathrm{N}=1969 ; \mathrm{R}^{2}=0,61 ; \mathrm{F}=311,3^{*}$ \\
\hline
\end{tabular}

Nota: Desvios padrão entre parênteses; ${ }^{*}$ ) significante a $1 \%$.

Fonte: Elaboração própria.

Salas comerciais (Tabela 6). Por tratar-se de imóveis como ambiente de trabalho, a quantidade de blocos e a quantidade de unidades por pavimento não são atributos físicos tão importantes como os são para apartamentos e flats. Coadunando com a expectativa teórica e literatura anteriormente aqui citada para outros segmentos, o consumidor parece procurar salas maiores, embora a sensibilidade do efeito marginal sobre o preço $(1,86 \%)$ seja menor do que o observado para flats. Também 
busca prédios com elevados gabaritos e alta concentração total de unidades, talvez em virtude da redução de custos de ocupação. Em termos locacionais, somente a distância ao Centro Nobre e a presença em um corredor comercial exercem influência primaz nos preços - o que é teoricamente esperado (renúncia a características qualitativas residenciais de vizinhança).

Angelo et al. (2004) encontraram resultados semelhantes para o mercado paulistano de salas comerciais referentes às variáveis área útil da sala e tamanho do prédio, o qual guarda equivalência com variáveis aqui investigadas, qual seja, a quantidade total de unidades e de pavimentos. Ainda, os resultados encontrados para as variáveis dimensão ou área, quantidade de pavimentos do edifício, localização e proximidade a corredor comercial mostram-se compatíveis com Clapp (1980) e Mill (1992), que realizaram trabalhos similares para as cidades de Los Angeles e Chicago nos Estados Unidos, respectivamente. A influência da quantidade total de pavimentos e da área útil de escritórios comerciais também foi evidenciada em estudo realizado por Ustaoğlu (2003) na cidade de Ankara, na Turquia.

O efeito dos subcentros como determinante à precificação de imóveis foi identificado nos trabalhos de Dantas (2003), Lucena (1985) e Rosiers e Thériault (1996). O sinal positivo da distância ao Centro de Negócios da cidade pode ser explicado pela característica imobiliária de formação de nichos geográficos: esse micromercado pode estar superofertado, ampliando preços das salas comerciais externas a essa circunscrição. A atividade comercial desse segmento pode explicar o fato de a variável nível de renda ter se mostrado significativa, o que é esperado pela teoria e verificado nos trabalhos de Dantas (2003), Fávero (2003) e Lucena (1985). Dessa forma, o consumo por sala comercial buscaria área de influência que ofereça resposta à atividade exercida, não sendo importante aqui condições relativas à ocupação familiar. Novamente, o sinal de saneamento mostra-se diferente do esperado, que pode denotar preocupação com externalidades, custos de serviços públicos e acentuado perfil residencial da região.

Tabela 5 - Estatística descritiva por características das variáveis de controle salas

\begin{tabular}{lccccccc}
\hline & Área & Pavimentos & Renda & Distância C. Nobre & Corredor & Saneamento & Unidades \\
\hline Média & 39.96 & 16.78 & 1126.77 & 0.69 & 0.92 & 0.4818 & 264.61 \\
Mediana & 37.00 & 18.00 & 1215.45 & 0.00 & 1.00 & 0.7277 & 146.00 \\
Máximo & 165.00 & 22.00 & 1215.45 & 5.57 & 1.00 & 0.9353 & 765.00 \\
Mínimo & 18.00 & 6.00 & 292.03 & 0.00 & 0.00 & 0.1163 & 28.00 \\
Desvio padrão & 14.92 & 4.06 & 253.15 & 1.68 & 0.27 & 0.2987 & 280.64 \\
\hline
\end{tabular}

Fonte: Elaboração própria.

Por fim, o ajuste do modelo deu-se com a exclusão das variáveis segurança e escolas, por serem seus coeficientes estatisticamente insignificantes. ${ }^{6}$ Quanto a isto, Ângelo et al. (2004) encon-

6 No caso de segurança, este resultado pode ser decorrência da proxy aqui utilizada, número de homicídios, cuja incidência primaz se dá em ambientes urbanos distintos ao de centro comerciais. 
traram resultados similares para a cidade de São Paulo, onde, à exceção das áreas Centro, Paulista e Jardins, a variável segurança, denotada por controle de acesso ao imóvel, mostrou-se irrelevante nas demais seis áreas constantes na amostra.

Tabela 6 - Estimativas da equação de preço para salas comerciais classificadas por características das variáveis de controle

\begin{tabular}{cc}
\hline Variáveis por Características & Coeficientes \\
\hline Constante & $9.6503^{*}$ \\
CARACTERíSTICAS FÍSICAS & $0.0186^{*}$ \\
Área do imóvel & $(0.0009)$ \\
Qtde. de pavimentos & $0.0128^{*}$ \\
& $(0.0025)$ \\
Unidades totais prédio & $0.00013^{*}$
\end{tabular}

CARACTERÍSTICAS LOCACIONAIS

$\begin{array}{ll}\text { Distância Centro Nobre } & 0.1020^{*}\end{array}$

$\begin{array}{ll}\text { Corredor comercial } & 0.1367^{\star}\end{array}$

CARACTERÍSTICAS ECONÔMICAS

$\begin{array}{ll}\text { Nível de renda } & 0.0005^{\star}\end{array}$

(8.69E-05)

Saneamento

$-0.4817^{*}$

Observações e estatísticas:

$N=1622 ; R^{2}=0,63 ; F=387,5^{*}$

Nota: Desvios padrão entre parênteses; $\left(^{*}\right)$ significante a $0,2 \%$.

Fonte: Elaboração própria.

Terrenos (Tabela 8, modelos 1 e 2). Dois modelos foram estimados com o intuito de captar o efeito de alguma característica financeira, no caso custo de oportunidade do capital (modelo 2). Para as características físicas, a importância da variável área correspondeu às expectativas. Para características locacionais, a presença em corredor atua significativamente nos preços, apesar do sinal diferente do esperado - o que pode indicar informação imperfeita, característica do mercado imobiliário (os dados são colhidos de classificados de periódicos locais). Economicamente, são importantes as variáveis limpeza, também indicada por Lucena (1985), o qual afirma acerca da necessidade de oferta de serviços públicos para valorizar semelhante ativo, a renda (de acordo com a teoria e trabalhos já citados para outros segmentos) e as escolas. Não foi importante a alta concentração domiciliar, talvez porque esse consumidor esteja preocupado com prospecção futura, desprezando a situação atual de densidade do bairro. Assim, para o consumo de terrenos urbanos, observa-se, além do nível de renda, o acesso à educação como indicadores de desenvolvimento local, facilitando a incorporação imobiliária, como identificado anteriormente por Fávero (2003), 
ao estudar segmento de consumidores de renda baixa, característica mais intensa na amostra aqui utilizada de terrenos urbanos. O sinal de saneamento apresentou-se diferente do esperado pela teoria, pois a oferta de serviços públicos desloca a curva de oferta. O segmento apresentou problemas de multicolinearidade de algumas variáveis (distância ao Centro Nobre, distância ao Centro Tradicional, coleta, densidade populacional, lazer, nobreza, praia, saúde, segurança, acessibilidade e verticalização), que foram excluídas.

Tabela 7 - Estatística descritiva por características das variáveis de controle terrenos

\begin{tabular}{lcccccc}
\hline & Área & Risco & Nível Vacância & Distância C. Tradicional & Densidade Populacional & Coleta \\
\hline Média & 2829.28 & 1.9376 & 0.1163 & 6.6156 & 60.6829 & 0.8331 \\
Mediana & 1000.00 & 2.0731 & 0.0900 & 7.3500 & 51.0000 & 0.9111 \\
Máximo & 52190.00 & 2.3799 & 1.0000 & 12.330 & 220.0000 & 0.9969 \\
Mínimo & 96.00 & 1.1975 & 0.0000 & 0.0000 & 3.0000 & 0.0980 \\
Desvio padrão & 5626.53 & 0.3696 & 0.1663 & 2.4132 & 44.6551 & 0.2325 \\
\hline
\end{tabular}

Fonte: Elaboração própria.

Outra ótica é incorporada aqui em um segundo modelo para terrenos ${ }^{7}$ (modelo 2 da Tabela 8). O agente de demanda migra para a utilidade de investimento do terreno a que estaria sujeito indistintamente qualquer imóvel componente da amostra. Nesse sentido, parece haver alteração da composição das variáveis: diferentes preços são formados quando se incorpora elementos financeiros. Há indícios de existir deslocamento na curva de indiferença, provavelmente indicando a substituição de atributos. Aqui, a vacância não possuiu significância estatística, o que poderia se qualificar preliminarmente como condizente com a teoria, uma vez que, do terreno, se espera basicamente valorização, podendo o quadro de ocupação do mercado assumir pouca importância. De acordo com Rosiers e Thériault (1996), há grau de instabilidade associado ao fenômeno da vacância. Note-se, por fim, que as variáveis anteriormente integrantes do modelo corredor, saneamento e escolas passaram a não ter mais significância estatística.

Coadunando ainda com os resultados encontrados para os segmentos anteriores, a clássica distância ao centro tradicional da cidade figura como determinante no preço de terrenos, enquanto o acúmulo de habitantes por metro quadrado, condição típica de bairros que acomodam conjuntos habitacionais ou favelas, poderia ser considerado como fator de realinhamento negativo de preços atribuíveis aos terrenos. Essa última característica de acúmulo de pessoas, e a conseqüente produção de resíduos vinculada ao perfil de bairro, pode explicar o preliminarmente inesperado sinal negativo encontrado para o índice de coleta de domicílios: a infra-estrutura pública de oferta de serviços geralmente busca atuar em pontos geográficos críticos, onde terrenos urbanos possuem menor valorização talvez pela presença de acentuada densidade, como se observa em conjuntos habitacionais de baixa renda ou favelas.

7 Devido a problema de colinearidade entre as variáveis, esta foi a maneira escolhida para realçar a significância de algumas variáveis, como risco (custo do capital). 
Quanto ao fator risco, na aquisição de terrenos, o efeito marginal sobre a redução do preço advinda de uma elevação de $10 \%$ no custo de oportunidade da taxa de rendimento no mercado financeiro é de 4,2\%, ou seja, cerca de três maior do que o verificado no segmento para apartamentos.

Tabela 8 - Estimativas das equações de preço para terrenos classificadas por características das variáveis de controle

\begin{tabular}{crr}
\hline Variáveis por Características & \multicolumn{2}{c}{ Coeficientes } \\
\cline { 2 - 3 } & \multicolumn{1}{c}{ Modelo 1 } & Modelo 2 \\
\hline Constante & $10.675^{*}$ & $11.075^{*}$ \\
& $(0.0733)$ & $(0.2597)$ \\
CARACTERÍSTICAS FíSICAS & & \\
Área & $0.0212^{*}$ & $0.0001^{*}$ \\
& $(0.0006)$ & $(2.04 \mathrm{E}-05)$
\end{tabular}

CARACTERÍSTICAS LOCACIONAIS

Corredor comercial $\quad-0.1752^{*}$

$(0.0232)$

CARACTERÍSTICAS ECONÔMICAS

Nível de renda

$8.61 \mathrm{E}-05^{*}$

$0.0016^{*}$

(287E-05)

$(0.0001)$

Saneamento

$-0.2274^{*}$

(0.0616)

Oferta de escolas

$232.59^{*}$

(29.9223)

CARACTERÍSTICAS FINANCEIRAS

Risco (oportunidade capital) $\quad-0.4749^{*}$

$(0.1265)$

Observações e estatísticas:

$N=539 ; R^{2}=0,73 ; F=286,8^{*} \quad N=539 ; R^{2}=0,39 ; F=114,3^{*}$

Nota: Desvios padrão entre parênteses; $\left(^{*}\right)$ significante a, no máximo, 0,2\%.

Fonte: Elaboração própria.

\section{CONClusões}

A análise microeconômica do perfil de demanda de um determinado mercado de ativos possui importância em auxiliar na identificação das preferências individuais, gerando menor assimetria de informações, tão comum ao complexo mercado imobiliário. O fato de se ter encontrado alguns resultados, embora estatisticamente robustos, mas contrários às expectativas teóricas ou aos de outros trabalhos similares, enriquece e contribui para sua relevância e continuada busca por novas investigações. 
Nessa perspectiva, o presente artigo teve por objetivo primordial a identificação das funções que regem as preferências individuais do consumidor do bem habitação em Fortaleza, cujo mercado foi segmentado em grupos individuais, formado por apartamentos, flats, salas comerciais e terrenos, tendo como fundamentação teórica a formação de preços hedônicos. As estimações revelaram que o consumidor de imóveis possui um perfil em que o nível de acessibilidade oferecido pela microlocalização ainda não se mostra como variável de importância para a determinação de preços de equilíbrio. A habitação, nesse sentido, parece criar os anéis concêntricos de oferecimento de acessibilidade e não o inverso, como se espera e ocorre com os investidores. Há evidências de que o consumidor de imóveis urbanos tem nos preços sua preocupação com as externalidades negativas causadas por alguns equipamentos urbanos, como é o caso das escolas (problemas de tráfego e poluição sonora), dos hospitais (lixo hospitalar) e até mesmo dos problemas ambientais (caso das praias). Por outro lado, os resultados levam a crer que há forte prioridade pelo nível de lazer oferecido pelo bairro. Também parece dar extrema importância à distância física aos dois principais centros de negócios da cidade, provavelmente em alguns segmentos substituindo sua necessidade de consumo de acessibilidade por esses fatores, tidos como prioritários. A variável segurança apresentou resultados significantes para ocupações residenciais, mostrando-se consonante com a literatura existente. Porém, no caso de flats e salas comerciais, os resultados podem ter sido influenciados pela proxy utilizada (homicídios), mais comum na periferia urbana, que não capta esse tipo de segmento. Por fim, o consumidor direto de serviços habitacionais parece estar atraído por regiões que ofertem uma boa estrutura urbana, mas sem necessariamente a presença massiva de grandes equipamentos, porém, dotada de amenidades ambientais no processo de consumo de serviços habitacionais.

O outro componente de demanda por serviços habitacionais, formado pelo público de investidores, parece agregar à sua cesta de bens fatores pontuados pelo binômio risco e retorno, renunciando a características marcantes, as quais anteriormente atuavam como determinantes na formação de preços. No caso desses investidores, variáveis importantes como distância ao centro de negócios, altura da edificação e quantidade de pavimentos parecem perder sua posição para atributos ligados ao comportamento financeiro do imóvel. Tais atributos financeiros, então, interagiriam com o portfólio de investimentos do demandante investidor e influenciariam a composição de sua cesta de bens, como mais uma heterogeneidade inerente ao bem habitacional, dentro desse complexo mercado de análise da economia urbana. 


\section{REFERÊNCIAS}

ABRAMO, P.; FARIA, T. C. Mobilidade residencial na cidade do Rio de Janeiro; considerações sobre os setores formal e informal do mercado imobiliário. In: ENCONTRO NACIONAL DE ESTUDOS POPULACIONAIS DA ABEP, 11. Anais. ABEP, Caxambu, 1998. 20 p.

ALONSO, W. Location and land Uue. Cambridge: Harward University Press, 1964.

AÑÃA, E. S. Utilização da terra como ativo de baixo risco, na diversificação de carteiras de investimento. Dissertação (Mestrado) - UFRS, Porto Alegre, 2000. 143 p.

ANDRADE, M. V.; RONDON, V. V. Uma estimação dos custos da criminalidade em Belo Horizonte. In: SEMINÁRIO SOBRE ECONOMIA MINEIRA, Belo Horizonte, 2002. 10 p.

ANGELO, C. F.; Fávero, L. P. L.; LUPPE, M. R. Modelos de preços hedônicos para a avaliação de imóveis comerciais no município de São Paulo. Revista de Economia e Administração, v. 3, n. 2, p. 97-110, 2004.

BAJARI, P.; KAHN M. E. Estimating housing demand with an application to explaining racial segregation in cities. Cambridge: National Bureau of Economic Research, 2003. (Working Paper 9891)

BALARINE, O. F. O. Determinação do impacto de fatores socioeconômicos na formação do estoque habitacional em Porto Alegre. Tese (Doutorado) - UFSC, Florianópolis, 1995. 125 p.

Contribuições macroeconômicas ao entendimento da formação de preços habitacionais locais. In: ENCONTRO NACIONAL DE ENGENHARIA DA PRODUÇÃO. Anais. Piracicaba: ENEGEP. 1997. $15 \mathrm{p}$.

BREALEY, R. A; MYERS, S. C. Princípios de finanças empresariais. 3. ed. Lisboa: McGraw-Hill, 1992.

BROWN J. N.; ROSEN, H. S. On the estimation of structural hedonic price models. Econométrica, v. 50, n. 3, p. 765-768, 1982.

CARVALHO JR., F. J. L.; LEMME, C. F. O impacto da violência criminal urbana sobre o preço dos imóveis residenciais na região da Tijuca, cidade do Rio de Janeiro: um estudo exploratório. Cadernos de Administração Rural (ESAL), FGV/EBAPE, Rio de Janeiro, v. 3, n. 3, p. 1-15, 2005.

CAVAlCANTE, M. G. Apartamentos residenciais: formação do valor em Fortaleza-CE. São Paulo: Annablume, 2002.

CHESHIRE, P.; SHEPPARD S. On price of land and the value of amenities. Economica, v. 62, p. 24767, 1995.

CLAPP, J. The intrametropolitan location of office activities. Journal of Regional Science, n. 20, p.387-399, 1980.

CRUZ, B. O.; SANTOS, C. H. M. A. Dinâmica dos mercados habitacionais metropolitanos: aspectos teóricos e uma aplicação para a Grande São Paulo. Brasília: IPEA, 2000. (Texto para Discussão, 713).

DAMODARAN, A. Avaliação de investimentos: ferramentas e técnicas para a determinação do valor de qualquer ativo. Rio de Janeiro: Qualitymark, 1997.

DANTAS, R.A. Engenharia de avaliações - uma introdução à metodologia científica. São Paulo: Pini, 1998.

Modelos espaciais aplicados ao mercado habitacional: um estudo de caso para a cidade de Recife. Tese (Doutorado) - UFPE, Recife, 2003. 114 p.

DIPASQUALE, D.; WHEATON, W. C. Housing dynamics and the futures of housing prices. Journal of Urban Economics, v. 35, p. 1-27, 1994. 
EKELAND, I.; HECKMAN, J.; NESHEIM, L. Identifying hedonic models. The American Economic Review, v. 92, n. 2, p. 304-309, 2002.

FARBER, S.; PÁEZ, A.; LONG, F. Spatial effects in hedonic price estimation: a case study in the city of Toronto: McMaster University, 2007. (Working Paper Series 20).

FÁVERO, L. P. L. Modelos de preços hedônicos aplicados a imóveis residenciais em lançamento no município de São Paulo. Dissertação (Mestrado) - USP, São Paulo, 2003. 65 p.

FERREIRA, M. F. S.; LEMOS, M. B. Vantagens comparativas das regiões metropolitanas de Salvador, Recife e Fortaleza no contexto regional. Fortaleza. Revista Econômica do Nordeste, v. 32, p. 691-708, 2001.

FERREIRA NETO, E. Estimação do preço hedônico: uma aplicação para o mercado imobiliário da cidade do Rio de Janeiro. Dissertação (Mestrado) - FGV, Rio de Janeiro, 2002. 48 p.

FURTADO, Bernardo Alves; RUIZ, Ricardo Machado. Um modelo com autômatos celulares para análise do espaço urbano. In: XXXIV ENCONTRO NACIONAL DE ECONOMIA. Anais. ANPEC, Salvador, 2006. 20p.

GONZÁLES, M. A. S. A formação do valor dos aluguéis de apartamentos residenciais na cidade de Porto Alegre. Dissertação (Mestrado) - UFRS, Porto Alegre, 1993. 138 p.

. A engenharia de avaliações na visão inferencial. São Leopoldo, Unisinos, 1997.

. Uma aplicação da metodologia científica de avaliação de imóveis na análise de viabilidade. In: ENCONTRO NACIONAL DE TECNOLOGIA DO AMBIENTE CONSTRUÍDO, 7. Anais. Florianópolis, 1998.

GONZÁLES, M. A. S.; FORMOSO, C. T. Análise conceitual das dificuldades na determinação de modelos de formação de preços através de análise de regressão. Revista de Engenharia Civil, v. 8, p. 65-75, 2000.

. A new approach to spatial analysis in CAMA. In: EUROPEAN REAL STATE SOCIETY CŌNFERENCE, 9. Anais. Glasgow, 2002.

GOODMAN, Allen C. Hedonic Prices. Disponível em: < http://www.econ.wayne.edu/agoodman/7800/ week6/Hedonic_Prices.ppt >. Acesso em: 29 jan. 2004.

GUJARATI, D. N. Econometria básica. 3. ed. São Paulo: Makron Books, 2000.

HADDAD, E. A. ; HERMANN, B. M. Muito além do jardim: mercado imobiliário e amenidades urbanas. São Paulo: USP, Dep. Economia, 2003. (Texto para Discussão, 04).

HERMANN, B. M. Estimando o preço implícito de amenidades urbanas: evidências para o município de São Paulo. Dissertação (Mestrado) - USP, São Paulo, 2003. 74 p.

INSTITUTO BRASILEIRO DE GEOGRAFIA E ESTATÍSTICA (IBGE). Síntese de Indicadores Sociais 2002. Rio de Janeiro, 2003.

JOHANSSON, Jörgen; SANDBERG, Krister. Estimation of hedonic prices for co-operative flats in the city of Umea with spatial autoregressive GMM. Centre for Regional Science, Umeå University, 2001. (Working Paper, 37).

KULLMANN, C. Real estate and its role in asset princing. Columbia: Faculty of Commerce and Business Administration, 2003. (Working Paper).

LANCASTER, K. J. A new approach to consumer theory. Journal of Political Economy, v. 74, n. 2, p. $132-$ 57, 1966. 
LIMA JR. J. R. Securitização de portfólios de base imobiliária. São Paulo: Departamento de Engenharia de Construção Civil. 1993. 23 p. (Boletim Técnico da Escola Politécnica da Universidade de São Paulo).

LUCENA, J. M. P. O mercado habitacional no Brasil. Rio de Janeiro: FGV, 1985. 185 p. (Série Teses).

MAURER, R.; PITZER M.; SEBASTIAN, S. Hedonic prices indices for the Paris housing market. Germany: Research Program Real Estate Finance, Goethe University, 2004. (Working Paper).

MEDEIROS, P. T. Aplicação de opções reais no mercado imobiliário residencial com enfoque na cidade do Rio de Janeiro. Dissertação (Mestrado) - PUC, Rio de Janeiro, 2001

MILL, E. Office rent determinants in the Chicago area. AREUEA Journal, n. 20, p. 273-287, 1992.

MIRANDA, Rubens Augusto; DOMINGUES, Edson Paulo. Jornada ao trabalho e escolhas residenciais na região metropolitana de Belo Horizonte. In: XII ENCONTRO REGIONAL DE ECONOMIA, Anais. ANPEC/BNB, Fortaleza, 2007. 24p.

O’SULLIVAN, A. Urban economics. 3. ed. Homewood, Il: Irwin Editors, 1996.

VARIAN, H. R. Microeconomia: princípios básicos. 5. ed. Rio de Janeiro: Ed. Campus, 2000.

PITTA, C. E. Risco e retorno de investimento imobiliário: um estudo do mercado de imóveis comerciais de São Paulo. Dissertação (Mestrado) - EAESP/FGV, São Paulo, 2000. 84 p.

PREFEITURA MUNICIPAL DE FORTALEZA (PMF). Lei de Uso e Ocupação do Solo - Lei n. 7.987/1996; Plano Diretor de Desenvolvimento Urbano - Lei no 7.061/1992; Síntese Diagnóstica do Município. Disponível em <http://www. fortaleza.ce.gov.br >. Acesso em: 24 jan. 2004.

RAMANATHAN, R. Introductory econometrics with applications. 3. ed. The Dryden Press, Harcourt College Publishers, 1995.

ROSEN, S. Hedonic prices and implicit markets: product differentiations in pure competition. Journal of Political Economy, v. 82, p. 34-55, 1974.

ROSIERS, D. F.; THÉRIAULT, M. Rental amenities and the stability of hedonic prices: a comparative analysis of five market segments. The Journal of Real Estate Research, v. 12, n. 1, p. 17-36, 1996.

SERRA, Maurício Aguiar; TEIXEIRA, Evandro Camargos. O impacto da criminalidade no valor da locação de imóveis: o caso de Curitiba. Economia e Sociedade, UNICAMP, v. 15, p. 175-207, 2006.

SMITH, L. A note on the price adjustment mechanism for rental housing. The American Economic Review. v. 64, n. 3, p. 478-498, 1974.

SOUSA FILHO, E. H. O mercado imobiliário convencional da cidade de Fortaleza como alternativa para investidores institucionais no período pós-Real. Monografia (Especialização em Administração Financeira) - Universidade Estadual do Ceará, Fortaleza, 2002.

TAUCHEN, H.; WITTE, A. D. Estimating hedonic models: implication of the theory. National Bureau of Economic Research, Cambridge, 2001. (Working Paper, 271).

USTAOĞLU, E. Hedonic price analysis of office rents: a case study of the office market in Ankara. Dissertação (Mestrado) - Middle East Technical University, 2003. 106 p.

VARIAN, H. R. Microeconomia: princípios básicos. 5. ed. Rio de Janeiro: Ed. Campus, 2000.

WEBB, R.; FISHER, J. Development of an effective rent (lease) index for the Chicago CBD. Jornal of Urban Economics, n. 39, p. 1-19, 1996. 


\section{ANEXO - ESPECIFICAÇÕES ALTERNATIVAS PARA OS PREÇOS DE APARTAMENTOS, FLATS, SALAS COMERCIAIS E TERRENOS}

Tabela A1 - Apartamento: forma funcional LINEAR

\begin{tabular}{lc}
\hline Variáveis & Coeficientes \\
\hline Constante & $-29076.43^{* *}$ \\
Área & $(18087.52)$ \\
Densidade domiciliar & $1757.33^{*}$ \\
& $(63.93)$ \\
Densidade populacional & $3780.87^{*}$ \\
Qtde. de pavimentos & $(702.91)$ \\
& $-1028.88^{*}$ \\
Saneamento & $(228.47)$ \\
& $1448.73^{*}$ \\
Distância Centro Tradicional & $(332.87)$ \\
& $-18090.60^{*}$ \\
Observações e estatísticas & $(6417.16)$ \\
\end{tabular}

Nota: Desvios padrão entre parênteses; $(*)$ significante a $1 \% ;(* *)$ significante a $5 \%$.

Tabela A2 - Apartamento: forma funcional LOG-LOG

\begin{tabular}{lc}
\hline Variáveis & Coeficientes \\
\hline Constante & $8.6907^{*}$ \\
& $(0.4427)$ \\
Área do imóvel & $0.8328^{*}$ \\
Distância centro nobre & $(0.0811)$ \\
& $-0.2285^{*}$ \\
Apto. por pavimento & $(0.0217)$ \\
Qtde. de blocos & $-0.1377^{\star *}$ \\
& $(0.0637)$ \\
Oferta de lazer & $-0.169562^{*}$ \\
Oferta de saúde & $(0.0249)$ \\
& $0.1174^{*}$ \\
Risco (oportunidade de capital) & $(0.0166)$ \\
& $-0.0596^{*}$ \\
Observações e estatísticas & $(0.0129)$ \\
\hline
\end{tabular}

Nota: Desvios padrão entre parênteses; $(*)$ significante a $1 \% ;(* *)$ significante a $5 \%$. 
Tabela A3 - Flats: forma funcional LINEAR

\begin{tabular}{lc}
\hline Variáveis & Coeficientes \\
\hline Constante & $-670962.2^{*}$ \\
Área do imóvel & $(27270.47)$ \\
Qtde de pavimentos & $3452.83^{*}$ \\
& $(85.60)$ \\
Renda & $1553.84^{*}$ \\
Distância aldeota & $(380.55)$ \\
& $88.5289^{*}$ \\
Apto. por pavimento & $(11.02)$ \\
Coleta & $110743.9^{*}$ \\
Corredor comercial & $(6341.06)$ \\
& $4744.35^{*}$ \\
Saneamento & 320.78 \\
& $380423.9^{*}$ \\
Oferta de escolas & $(24580.6)$ \\
& $14908.82^{*}$ \\
\hline Observações e estatísticas & $(2444.07)$ \\
\hline
\end{tabular}

Nota: Desvios padrão entre parênteses; $(*)$ significante a $1 \%$.

Tabela A4 - Flats: forma funcional LOG-LOG

\begin{tabular}{lc}
\hline Variáveis & Coeficientes \\
\hline Constante & $25.1391^{*}$ \\
Área do imóvel & $(0.7946)$ \\
& $1.259883^{*}$ \\
Qtde. de pavimentos & $(0.0258)$ \\
Renda & $0.2482^{*}$ \\
Distância Centro Nobre & $(0.0451)$ \\
& $-2.4317^{*}$ \\
Distância Centro Tradicional & $(0.1070)$ \\
& $-2.2254^{*}$ \\
Aptos. por pavimento & $(0.0934)$ \\
Coleta & $-0.9497^{*}$ \\
Unidades totais & $(0.0305)$ \\
& $0.7319^{*}$ \\
\hline Observações e estatísticas & $(0.0453)$ \\
\hline
\end{tabular}

Nota: Desvios padrão entre parênteses; $\left({ }^{*}\right)$ significante a $1 \%$. 
Tabela A5 - Salas comerciais: forma funcional LINEAR

\begin{tabular}{lc}
\hline Variáveis & Coeficientes \\
\hline Constante & $15174.17^{* *}$ \\
& $(6984.90)$ \\
Área do imóvel & $2768.23^{*}$ \\
& $(193.67)$ \\
Distância Centro Nobre & $-6584.51^{*}$ \\
& $(1066.61)$ \\
Saneamento & $-35295.99^{*}$ \\
& $(3073.77)$ \\
Unidades totais & $55.92337^{*}$ \\
& $(5.33)$ \\
Nobreza & $-44520.72^{*}$ \\
& $(5581.87)$ \\
\hline Observações e estatísticas & $\mathrm{N}=1622 ; \mathrm{R}^{2}=0,64 ; \mathrm{F}=597,5^{*}$ \\
\hline
\end{tabular}

Nota: Desvios padrão entre parênteses; $(*)$ significante a $1 \% ;(* *)$ significante a $5 \%$.

Tabela A6 - Salas comerciais: forma funcional LOG-LOG

\begin{tabular}{lc}
\hline Variáveis & Coeficientes \\
\hline Constante & $7.2284^{*}$ \\
& $(0.1311)$ \\
Área do imóvel & $0.9425^{*}$ \\
& $(0.0357)$ \\
Qtde. de pavimentos & $0.1862^{*}$ \\
Densidade domiciliar & $(0.0211)$ \\
& $-0.0445^{*}$ \\
Saneamento & $(0.0100)$ \\
& $-0.1566^{*}$ \\
Observações e estatísticas & $(0.0083)$ \\
\hline
\end{tabular}

Nota: Desvios padrão entre parênteses; $\left(^{*}\right)$ significante a $1 \%$. 


\section{Tabela A7 - Terrenos: forma funcional LINEAR}

\begin{tabular}{lc}
\hline Variáveis & Coeficientes \\
\hline Constante & $682205.6^{*}$ \\
Área & $(145966.4)$ \\
Nível de vacância & $51.0839^{*}$ \\
& $(13.39)$ \\
Risco (oportunidade de capital) & $-159763.3^{* *}$ \\
Coleta & $(89088.76)$ \\
& $-206984.9^{*}$ \\
Distância Centro Tradicional & $(67767.52)$ \\
& $-159763.3^{* *}$ \\
Praia & $(67767.52)$ \\
& $-30853.41^{*}$ \\
Nobreza & $(67767.52)$ \\
& $171899.5^{*}$ \\
\hline Observações e estatísticas & $(57410.43)$ \\
\hline
\end{tabular}

Nota: Desvios padrão entre parênteses; $(*)$ significante a $1 \% ;(* *)$ significante a $5 \%$.

\section{Tabela A8 - Terrenos: forma funcional LOG-LOG}

\begin{tabular}{lc}
\hline Variáveis & Coeficientes \\
\hline Constante & 7.4091 \\
& $0.3363)$ \\
Área do imóvel & 0.9378 \\
& $(0.0362)$ \\
Risco (oportunidade de capital) & -0.6426 \\
& $(0.1480)$ \\
Distância Centro Tradicional & -1.1259 \\
Coleta & $(0.1169)$ \\
& -0.3778 \\
Verticalização & $(0.0713)$ \\
& 0.1639 \\
Observações e estatísticas & $(0.0223)$ \\
\hline
\end{tabular}

Nota: Desvios padrão entre parênteses; $\left(^{*}\right)$ significante a $1 \%$. 